\title{
Tamm-Horsfall protein in recurrent calcium kidney stone formers with positive family history: abnormalities in urinary excretion, molecular structure and function
}

\author{
Markus Jaggi $\cdot$ Yasushi Nakagawa $\cdot$ Ljerka Zipperle $\cdot$ \\ Bernhard Hess
}

Received: 14 November 2006 / Accepted: 10 February 2007 / Published online: 8 March 2007

(C) Springer-Verlag 2007

\begin{abstract}
Tamm-Horsfall protein (THP) powerfully inhibits calcium oxalate crystal aggregation, but structurally abnormal THPs from recurrent calcium stone formers may promote crystal aggregation. Therefore, increased urinary excretion of abnormal THP might be of relevance in nephrolithiasis. We studied 44 recurrent idiopathic calcium stone formers with a positive family history of stone disease $\left(\mathrm{RCSF}_{\text {fam }}\right)$ and 34 age- and sex-matched healthy controls (C). Twenty-four-hour urinary THP excretion was measured by enzyme linked immunosorbent assay. Structural properties of individually purified THPs were obtained from analysis of elution patterns from a Sepharose 4B column. Sialic acid (SA) contents of native whole 24-h urines, crude salt precipitates of native urines and individually purified THPs were measured. THP function was studied by measuring inhibition of $\mathrm{CaOx}$ crystal aggregation in vitro ( $\mathrm{pH} 5.7,200 \mathrm{mM}$ sodium chloride). Twenty-fourhour urine excretion of THP was higher in $\mathrm{RCSF}_{\text {fam }}$ $(44.0 \pm 4.0 \mathrm{mg} / \mathrm{day})$ than in $\mathrm{C}(30.9 \pm 2.2 \mathrm{mg} /$ day,
\end{abstract}

M. Jaggi · L. Zipperle $\cdot$ B. Hess

Renal Stone Clinic and Stone Research Laboratory,

Policlinic of Internal Medicine, University Hospital,

Berne, Switzerland

Y. Nakagawa

Kidney Stone Laboratory,

University of Chicago, Chicago, IL, USA

M. Jaggi

Department of Anesthesiology,

Kantonsspital, 6000 Lucerne, Switzerland

B. Hess $(\bowtie)$

Internal Medicine and Nephrology, Klinik Im Park,

Bellariastrasse 38, 8038 Zurich, Switzerland

e-mail: bernhard.hess@hirslanden.ch
$P=0.015)$. Upon salt precipitation and lyophilization, elution from a Sepharose $4 \mathrm{~B}$ column revealed one major peak (peak A, cross-reacting with polyclonal anti-THP antibody) and a second minor peak (peak $\mathrm{B}$, not cross-reacting). THPs from $\mathrm{RCSF}_{\text {fam }}$ eluted later than those from C $(P=0.021)$, and maximum width of THP peaks was higher in $\mathrm{RCSF}_{\text {fam }}$ than in $\mathrm{C}(P=0.024)$. SA content was higher in specimens from $\mathrm{RCSF}_{\text {fam }}$ than from C, in native 24-h urines $(207.5 \pm 20.4 \mathrm{mg}$ vs. $135.2 \pm 16.1 \mathrm{mg}, P=0.013)$ as well as in crude salt precipitates of 24-h urines $(10.4 \pm 0.5 \mathrm{mg}$ vs. $7.4 \pm 0.9 \mathrm{mg}, \quad P=0.002$ ) and in purified THPs (75.3 $\pm 9.3 \mu \mathrm{g} / \mathrm{mg}$ vs. $48.8 \pm 9.8 \mu \mathrm{g} / \mathrm{mg}$ THP, $P=0.043)$. Finally, inhibition of calcium oxalate monohydrate crystal aggregation by $40 \mathrm{mg} / \mathrm{L}$ of THP was lower in $\mathrm{RCSF}_{\text {fam }}$ $(6.1 \pm 5.5 \%$, range -62.0 to $+84.2 \%)$ than in $\mathrm{C}$ $(24.9 \pm 6.0 \%$, range -39.8 to $+82.7 \%), P=0.022$, and only 25 out of $44(57 \%)$ THPs from RCSF fam were inhibitory (positive inhibition value) vs. 25 out of 34 (74\%) THPs from $\mathrm{C}, P<0.05$. In conclusion, severely recurrent calcium stone formers with a positive family history excrete more THP than healthy controls, and their THP molecules elute later from an analytical column and contain more SA. Such increasingly aggregated THP molecules predispose to exaggerated calcium oxalate crystal aggregation, an important prerequisite for urinary stone formation.

Keywords Nephrolithiasis - Positive family history · Calcium oxalate · Tamm-Horsfall protein · Sialic acid · Crystal aggregation inhibition

\section{Introduction}

Tamm-Horsfall protein (THP) is the most abundant urinary protein in healthy humans $[1,2]$. Over the years, THP has 
been described as a regulator of intrarenal cytokines, a contributor to tubulointerstitial renal disease, a trigger of cast nephropathy in multiple myeloma and a natural defense against bacterial infection in the urinary tract [1]. Most recent studies have emphasized the role of THP as a general defense factor against uropathogenic microorganisms, especially type 1 fimbriated Escherichia coli $[3,4]$. THP inhibits apoptosis and chemotaxis of isolated polymorphonuclear leukocytes, whereas phagocytosis is stimulated [5].

In addition, for many years, THP has been known for its involvement in urinary crystallization and stone formation. This has most recently been emphasized by the demonstration of a dramatic increase in spontaneous calcium oxalate crystal formation in THP knockout mice in comparison with wild-type mice, at least under conditions of excessive calcium and oxalate intake [6]. In human urine, crystal nucleation occurs opportunistically and quite abundantly [7], in normals and stone formers alike [8]. Whereas growth of nucleated microcrystals, at least for calcium oxalate, is too slow to produce particles of clinically relevant sizes, it is by means of crystal aggregation that larger particles form $[7,9]$. Particle formation in the urinary tract occurs under exquisite control of macromolecular modulators of crystallization $[10,11]$, i.e., particles form as a result of intimate interactions between newly forming inorganic crystal surfaces and organic macromolecules [10, 11]. In animal models, the synthesis of THP as well as other urinary macromolecules by renal cells is increased upon exposure to high oxalate concentrations or calcium oxalate crystals [10]. By reversibly binding at newly forming crystal surfaces, THP strongly enhances electrostatic surface charge and viscous binding forces, whereby it affects the process of crystal aggregation [11, 12].

However, controversy exists as to whether THP is a promoter or an inhibitor of the aggregation of calcium oxalate crystals in human stone formers. In vitro, urine-like concentrations of THP powerfully inhibit crystal aggregation [11], but rising concentrations of calcium, sodium, hydrogen ions and of THP itself progressively decrease its inhibitory activity [12]. Under urine-like conditions of low $\mathrm{pH}$ and high sodium concentration, some structurally abnormal THPs from recurrent calcium stone formers even become promoters of crystal aggregation in vitro [13, 14]. The molecular basis of this abnormality, which may be inherited [15], may involve posttranslational changes in glycosylation, which determine the biologic activity of THP [1]. Indeed, reduced terminally linked sialic acid (SA) has been found in a few stone former THPs [16].

Because high concentrations of THP molecules promote crystal aggregation at high urinary concentrations of calcium and/or sodium, increased urinary THP excretion rates might be of pathophysiological relevance in nephrolithiasis. However, we have demonstrated that urinary THP excretion was not different from normal subjects in non-selected recurrent kidney stone formers [17]. Since THP abnormalities may be inherited [15], the present study aimed at measuring THP excretion in highly selected recurrent idiopathic calcium renal stone formers with a positive family history of stone disease $\left(\mathrm{RCSF}_{\text {fam }}\right)$, in comparison with healthy controls. Furthermore, we wanted to evaluate structural and functional properties of individually purified THP molecules from $\mathrm{RCSF}_{\text {fam }}$ and healthy controls.

\section{Subjects and methods}

Study subjects

A total of 78 subjects, 44 recurrent calcium stone formers with a positive family history $\left(\mathrm{RCSF}_{\text {fam }}\right)$, and 34 age- and sex-matched controls (C), were studied. Except for one $\mathrm{C}$ and one $\mathrm{RCSF}_{\text {fam }}$, no materials from subjects who had participated in our previous study on THP abnormalities in calcium oxalate nephrolithiasis [15] were used for the present experiments. Out of 254 consecutive stone formers originally referred to the Renal Stone Clinic at the University of Berne, Switzerland, for metabolic evaluation over a period of 3.25 years, we identified 35 (13.8\%), 31 men and four women, with a positive family history for kidney stone disease (i.e., patients indicated a history of kidney stones in parents, grandparents, siblings, uncles or aunts) and meeting the following criteria: (1) recurrent calcium nephrolithiasis, i.e., passage from at least two calcium-containing stones, defined either by stone analysis (X-ray diffraction or infrared spectroscopy) or disappearance of opaque material on conventional radiographs; (2) idiopathic calcium stone disease, i.e., patients with or without idiopathic hypercalciuria, hyperoxaluria, hyperuricosuria or hypocitraturia; (3) normal renal function, i.e., plasma creatinine concentration less than $115 \mu \mathrm{mol} / \mathrm{L}$. Nine additional patients (six men, three women) meeting identical criteria were recruited from the Kidney Stone Laboratory at the University of Chicago for additional work-up of individual THP molecules. Excluded were all patients who exhibited well-defined causes of hypercalciuria (primary hyperparathyroidism, hypercalcemia associated with malignancy or immobilization, excess intake of vitamin D, sarcoidosis, renal tubular acidosis and medullary sponge disease), hyperoxaluria (primary hyperoxaluria, malabsorption with steatorrhea due to inflammatory bowel disease or short bowel syndrome) or hypocitraturia (renal tubular acidosis, malabsorption with steatorrhea or chronic urinary tract infection). In total, 44 $\mathrm{RCSF}_{\text {fam }}, 37$ men and seven women, were selected for studies. Their mean age was $43.4 \pm 1.6$ years (range 27-67), and they were severely recurrent stone formers, having formed a mean of $10.8 \pm 2.0$ stones (range 2-50). All 
medications possibly interfering with urinary determinants of THP excretion, i.e., calcium, citrate and uric acid [17], were discontinued at least 2 weeks before urine collection.

In comparison, a total of 34 controls (C), 25 men and nine women, were studied. Twenty-six (21 men and five women) control subjects were recruited from the University of Berne, and eight (four men, four women) from the Kidney Stone Laboratory of the University of Chicago. Their mean age was $39.1 \pm 1.7$ years (range 23-69), not different from $\mathrm{RCSF}_{\text {fam }}$. All control subjects were without a personal or family history of renal stone formation and not were taking any medication interfering with urinary determinants of THP excretion.

\section{Experimental procedures}

Table 1 summarizes all experimental procedures that are outlined in detail in the subsequent paragraphs. Except for 24-h excretion rates of THP, routine 24-h urine chemistries are not reported here, since the purpose of this study was to investigate individual THP molecules irrespective of 24-h urine compositions.

\section{Measurements of urinary Tamm-Horsfall protein}

For logistic reasons, 24-h excretion rates of urinary THP were measured in only one 24-h urine specimen of all subjects from the University of Berne (35 RCSF fam, $26 \mathrm{C}$ ). It has to be acknowledged that the day-to-day variability for THP in human urine amounts to $11 \%$ [18]. As previously described [17], THP was measured by a commercially available indirect non-competitive enzyme-linked immunosorbent assay (Syn ${ }^{\text {elisa }}$ Tamm-Horsfall protein, Pharmacia \& Upjohn/Elias Diagnostics, Freiburg, Germany), whereby monoclonal mouse anti-human THP antibodies, immobilized on pins, bind THP antigen from standards (0-3.5-820-50-120 mg/L in phosphate-buffered saline) and urine samples. The antigen-antibody complexes associate with an enzyme-labeled polyclonal sheep anti-human THP antibody, which subsequently converts added substrate to form a colored solution, monitored at $492 \mathrm{~nm}$.

Using this method, normal urinary excretion rates of THP have been found to be $9.3-35.0 \mathrm{mg} /$ day for men and 9.0-36.3 mg/day for women, respectively (5th-95th percentile). All freshly collected 24 -h urines were carefully shaken for $2 \mathrm{~min}$ at room temperature in order to avoid losing large THP polymers for analysis due to settling. Immediately thereafter, $10 \mu \mathrm{L}$-aliquots were aspired and diluted 1:100 with the denaturing sample buffer supplied with the ELISA kit. All incubations were carried out at room temperature, and measurements were performed in duplicate. Coefficients of variation were $5.0-5.2 \%$ for intra-assay variability and $7.8-9.2 \%$ for inter-assay variability.
Table 1 Summary of experimental procedures applied and materials used throughout the study. For details, see Sect. "Subjects and methods"

THP measurements (ELISA):

- Native 24-h urines (35 $\mathrm{RCSF}_{\text {fam }}$ and $26 \mathrm{C}$ )

Chromatography (24-h urines of all 78 study subjects):

Whole urines $+0.58 \mathrm{M} \mathrm{Nacl} \Rightarrow$ centrifugation

$\Rightarrow$ dialysis against $\mathrm{H}_{2} \mathrm{O}(3 \mathrm{x}) \Rightarrow$ lyophilization

$+4 \mathrm{M} \mathrm{Urea} / 0.02 \mathrm{Na}$-Phospate $\Rightarrow$ passage through Sepharose

$4 \mathrm{~B}$ column $\Rightarrow$ lyophilization of major peak A (= THP) +

minor peak $\mathrm{B}$

Cross-reaction with THP antibody:

-Peaks A and B (materials from $7 \mathrm{RCSF}_{\text {fam }}$ and $7 \mathrm{C}$ )

Sialic acid determination by acid hydrolysis:

-Native 24-h urines (35 RCSF fam and $26 \mathrm{C}$ )

-Crude salt precipitates of 24-h urines (35 $\mathrm{RCSF}_{\text {fam }}$ and $26 \mathrm{C}$ )

-ALL 78 peak A lyophilizates (= THP)

-17 peak B lyophilizates (9 RCSF and $8 \mathrm{C}$ )

Crystal aggregation inhibition in vitro:

$-40 \mathrm{mg} / \mathrm{l}$ of all 78 lyophilized THPs (peak A) at pH 5.7, $200 \mathrm{mM}$

$\mathrm{Nacl}$

Purification/elution pattern of THPs

\section{General procedure}

From individual whole 24-h urines, THP was precipitated by adding $0.58 \mathrm{M} \mathrm{NaCl}$ according to Fletcher et al. [19]. Salt precipitates were dialyzed three times for $24 \mathrm{~h}$ against distilled water at $4{ }^{\circ} \mathrm{C}$ and then lyophilized. This purified material was subsequently dissolved in a solution containing $4 \mathrm{M}$ urea and $0.02 \mathrm{M}$ sodium phosphate, $\mathrm{pH} 6.8$, whereby urea was recrystallized from $70 \%$ ethanol before use. Thereafter, the material was passed through a Sepharose 4B column (Sepharose 4B, $2 \mathrm{~cm} \times 100 \mathrm{~cm}$, Pharmacia, Switzerland), as previously described [13]. Eluates were collected by an automated fraction collector $(1.5 \mathrm{~mL} /$ tube), and absorbance of fractions was measured at $277 \mathrm{~nm}$ [14].

As demonstrated in Fig. 1 for two representative individuals (one $\mathrm{C}$, one $\mathrm{RCSF}_{\text {fam }}$ ), materials usually eluted as one major peak (peak A) and a second minor peak (peak B). Since only peak A material had originally cross-reacted in an ELISA with a polyclonal anti-THP antibody raised in rabbits (Biomedical Technologies, Stoughton, MA, USA), all elution fractions from peaks $\mathrm{A}$ were pooled, subsequently lyophilized and stored at $4^{\circ} \mathrm{C}$ for further experiments. For all individual eluates of THPs, maximum absorbance (i.e., maximum height of peaks), fraction numbers at maximum absorbance (i.e., peak position) and numbers of fractions from the beginning to the end of peaks (i.e., maximum width of peaks) on elution diagrams were 


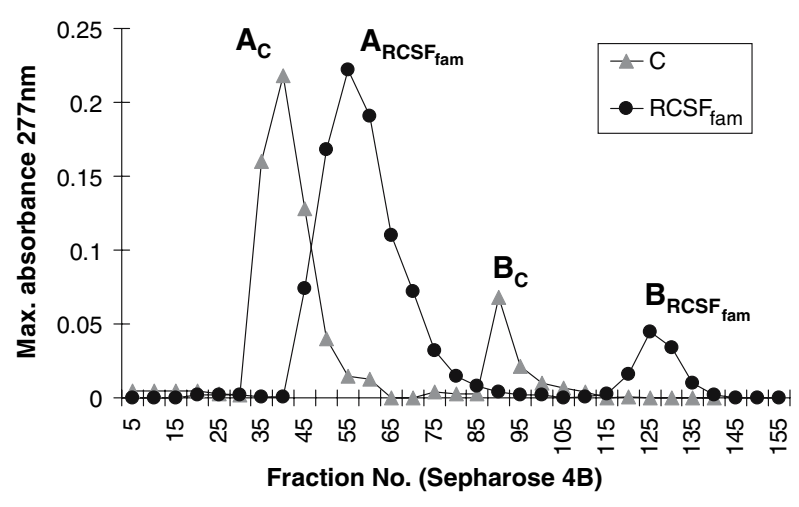

Fig. 1 Elution patters of salted-out and dialyzed/lyophilized materials on a Sepharose 4B column (two representative individuals, one $\mathrm{C}$ and one $\left.\mathrm{RCSF}_{\text {fam }}\right)$. For details, see text

registered. Maximum width of peaks A was taken as a rough estimate of the amount of eluted THP.

\section{Sialic acid measurements}

Sialic acid was measured using the thiobarbituric assay described by Aminoff [20]. Briefly, after oxidation with periodic acid $\left(25 \mathrm{mM}\right.$ in $\left.0.125 \mathrm{~N} \mathrm{H}_{2} \mathrm{SO}_{4}, \mathrm{pH} 1.2\right)$ and reduction of excess periodate with sodium arsenite (2 vol\% in $0.5 \mathrm{~N} \mathrm{HCl})$, 2-thiobarbituric acid $(0.1 \mathrm{M}$ aqueous solution, $\mathrm{pH}$ 9.0) is added and heated for $7.5 \mathrm{~min}$ in a boiling water bath. The colored solution is cooled on ice, followed by extraction with acid butanol (butan-1-ol, addition of 5 vol\% $12 \mathrm{~N} \mathrm{HCl}$ ). The absorbance at $549 \mathrm{~nm}$ in the butanol layer is directly proportional to the SA concentration, with a molar extinction of $70.7 \times 10^{3}$ [20]. A calibration curve was constructed by using $5-40 \mu \mathrm{g}$ of $\mathrm{N}$-acetyl-neuraminic acid in aqueous solution.

The SA content was measured in four types of specimens (Table 1).

\section{Native 24-h urines}

A sample of $0.5 \mathrm{~mL}$ of native $24-\mathrm{h}$ urine was directly used for the thiobarbituric assay, as described above. The amount of SA in whole 24-h urines was obtained from extrapolating the $\mathrm{SA}$ content in $0.5 \mathrm{~mL}$ whole urine to the respective 24-volume. This was performed in native urines of all subjects from the University of Berne.

\section{Crude salt-precipitates of 24-h urines}

To $20 \mathrm{~mL}$ of native 24 -h urines, $0.58 \mathrm{M} \mathrm{NaCl}(0.68 \mathrm{~g})$ was added. After stirring overnight and centrifugation at $5,000 \mathrm{rpm}$ for $15 \mathrm{~min}$, precipitates were separated from supernatants. Precipitates were then brought back to their original volume by adding distilled $\mathrm{H}_{2} \mathrm{O}$. In order to make sure that precipitates were richer in THP than supernatants, as assumed, we measured THP concentrations both in supernatants and precipitates from 22 subjects (11 RCSF, $11 \mathrm{C}$ ) by ELISA (described above) in a preliminary study. THP concentrations amounted to $15.5 \pm 2.3 \mathrm{mg} / \mathrm{L}$ in precipitates and $1.9 \pm 0.3 \mathrm{mg} / \mathrm{L}$ in supernatants, respectively $(P=0.0001)$, thus proving that major amounts of THP were present in precipitates. Therefore, SA contents were subsequently determined in crude salt precipitates of all 24-h urines from subjects of the University of Berne.

Hydrolysis of precipitates was performed by adding $50 \mathrm{mM} \mathrm{H}_{2} \mathrm{SO}_{4}$ and incubating at $80^{\circ} \mathrm{C}$ for $60 \mathrm{~min}$. Thereafter, $\mathrm{pH}$ was adjusted to 5.5. After dialysis against $30 \mathrm{~mL}$ of $\mathrm{H}_{2} \mathrm{O}$ for $24 \mathrm{~h}$, diffusates were lyophilized and then redissolved in $1 \mathrm{~mL}$ water. In $0.5 \mathrm{~mL}$ of this solution, SA content was measured according to Aminoff [20] as described above, and the amount of SA in the precipitate of the whole 24-h urine was calculated.

Purified THPs (peaks A eluting from Sepharose 4B column)

Two milligrams of all lyophilized THPs (major peak A, see above) were dissolved in $2 \mathrm{~mL}$ of $50 \mathrm{mM} \mathrm{H}_{2} \mathrm{SO}_{4}$ overnight. Undissolved material was removed by centrifugation at 3,000 rpm for $10 \mathrm{~min}$. Thereafter, THP concentration in solution was measured by the extinction at $277 \mathrm{~nm}[13,14]$. Hydrolysis was then obtained by incubating $1 \mathrm{~mL}$ of this THP solution at $80^{\circ} \mathrm{C}$ for $60 \mathrm{~min}$. After adjustment of the $\mathrm{pH}$ to 5.5 , the sample was dialyzed for $24 \mathrm{~h}$ against $30 \mathrm{~mL}$ of $\mathrm{H}_{2} \mathrm{O}$, and the diffusate was lyophilized. The lyophilisates were redissolved in $1 \mathrm{~mL}$ of $\mathrm{H}_{2} \mathrm{O}$, and $\mathrm{SA}$ content was determined in $0.5 \mathrm{~mL}$ of this solution as described above. Subsequently, the SA content per milligram of lyophilized THP was calculated.

\section{Second peaks (peaks B eluting from the Sepharose $4 B$ column)}

Of original salt precipitates from subjects recruited at the University of Chicago, material eluting as second peak (peak B) was additionally pooled and lyophilized, and the SA content per milligram of this material was also calculated.

Measurements of calcium oxalate crystal aggregation

The aggregation of calcium oxalate monohydrate (COM) crystals in vitro was measured as previously described in detail [13-15]. Briefly, COM crystals $(0.7 \mathrm{mg} / \mathrm{mL})$ in a solution containing $200 \mathrm{mM} \mathrm{NaCl}$ and $10 \mathrm{mM}$ sodium acetate, $\mathrm{pH} 5.70$, are stirred overnight at $37^{\circ} \mathrm{C}$ under constant stirring $(850 \mathrm{rpm})$ in order to obtain a homogeneous slurry. After preincubation with small amounts ( $<5$ vol\%) of aque- 
ous solutions of THPs in order to reach final assay concentrations of $40 \mathrm{mg} / \mathrm{L}$, additional particle aggregation is induced with stirring at slower speed $(500 \mathrm{rpm})$ for $180 \mathrm{~s}$ in a spectrophotometric cuvette [13-15]. Thereafter, spontaneous particle sedimentation is monitored at $620 \mathrm{~nm}$, whereby the rate of decrease of absorbance at $620 \mathrm{~nm}$ over time, called turbidity slope $T_{\mathrm{S}}$, reflects particle size [13-15]. The $T_{\mathrm{S}}$ values in control slurries $\left(T_{\mathrm{SC}}\right)$ are taken as $100 \%$ aggregation, and percent crystal aggregation in presence of THPs is calculated as $\left(T_{\mathrm{S}} / T_{\mathrm{SC}}\right) \times 100$. Percent inhibition of COM crystal aggregation is calculated as $100 \%-\%$ aggregation, whereby a negative inhibitory activity indicates promotion of COM crystal aggregation [13-15].

Crystal aggregation experiments were performed in the presence of $40 \mathrm{mg} / \mathrm{L}$ lyophilized and dissolved THP (peak A material, see above) of all 78 study subjects.

\section{Statistics}

All values are presented as mean \pm SE. For comparisons between groups, non-parametric Mann-Whitney $U$-test was used, whereas Wilcoxon signed-rank test was applied for within-group comparisons, and observed frequencies were compared by $\chi^{2}$ statistics. Simple and multiple linear regression analysis was performed for correlation studies.

\section{Results}

Measurements of urinary Tamm-Horsfall protein

As shown in Fig. 2, 24-h urine excretion rate of THP was higher in $\operatorname{RCSF}_{\text {fam }}(44.0 \pm 4.0 \mathrm{mg} /$ day $)$ than in $\mathrm{C}$ $(30.9 \pm 2.2 \mathrm{mg} / \mathrm{day}, P=0.015)$. When considering all 61 subjects in whom urinary THP had been measured (35 $\mathrm{RCSF}_{\text {fam }}, 26 \mathrm{C}$ ), THP excretion rate was positively correlated with the amount of SA detected in crude salt precipitates of whole 24-h urines (see below), $R=0.565$, $P=0.0001$. This correlation also persisted when calculated separately for $\operatorname{RCSF}_{\text {fam }}(R=0.691, P=0.0001)$ and $\mathrm{C}$ ( $R=0.490, P=0.011)$, respectively.

\section{Purification/elution pattern of THPs}

As depicted in Fig. 1 for two representative individuals, elution from the column was delayed in THPs (peaks A) from $\mathrm{RCSF}_{\text {fam }}$ (fraction number at maximum absorbance $53.5 \pm 2.1)$ in comparison with THPs from C (46.1 \pm 1.9 , $P=0.021)$. The maximum peak absorbance was not different between $\mathrm{RCSF}_{\text {fam }} \quad(0.267 \pm 0.067)$ and $\mathrm{C}$ $(0.244 \pm 0.020)$. However, maximum width of peaks $\mathrm{A}$, i.e., number of fractions from the beginning to the end of the eluted peak A material - a rough measure of the amount of eluted THP - was higher in $\operatorname{RCSF}_{\text {fam }}(45.1 \pm 3.4)$ than in $\mathrm{C}(34.5 \pm 2.0, P=0.024)$. The higher amounts of THP daily excreted in urine by $\mathrm{RCSF}_{\text {fam }}$, as measured by ELISA (Fig. 2), were marginally and positively correlated with the widths of peak A $(R=0.255, P=0.049)$.

For peak B materials, there was a trend for coming off the column later in $\mathrm{RCSF}_{\text {fam }}$ (fraction number at maximum absorbance $114.4 \pm 3.6$ ) than in $\mathrm{C}$ (fraction number $107.4 \pm 3.8$ ), and maximum absorbance of peaks $B$ tended to be lower in $\operatorname{RCSF}_{\text {fam }}(0.137 \pm 0.050)$ than in $\mathrm{C}$ $(0.159 \pm 0.064, P=0.072)$.

Sialic acid measurements

Figure 3 depicts the results of SA measurements. In native whole 24-h urines (Fig. 3 a), the total amount of SA excreted in urines from healthy controls was $135.2 \pm$ $16.1 \mathrm{mg} / 24 \mathrm{~h}$, lower than in $\mathrm{RCSF}_{\text {fam }}$ who excreted $207.5 \pm 20.4 \mathrm{mg} / 24 \mathrm{~h}(P=0.013)$. SA contents in crude salt precipitates of 24-h urines, presumably THP, were $7.4 \pm 0.9 \mathrm{mg} / 24 \mathrm{~h}$ in controls and $10.4 \pm 0.5 \mathrm{mg} / 24 \mathrm{~h}$ in $\mathrm{RCSF}_{\text {fam }}(P=0.002$, Fig. 3b, left $)$. Measured in lyophilisates of peaks A (=THP), the SA content was $48.8 \pm 9.8 \mu \mathrm{g} / \mathrm{mg}$ THP in C, significantly lower than in $\mathrm{RCSF}_{\text {fam }} \quad(75.3 \pm 9.3 \mu \mathrm{g} / \mathrm{mg}$ THP, $P=0.043$, Fig. $3 \mathrm{~b}$, right). The amount of THP daily excreted in urine was positively related to the amount of SA detected in crude salt precipitates of urines (presumably THP), $R=0.565$, $P=0.0001$.

Sialic acid content of peak B material, measured in selected subjects recruited at the University of Chicago (seven $\mathrm{C}$, seven $\mathrm{RCSF}_{\text {fam }}$ ), again tended to be lower in $\mathrm{C}$ $(47.6 \pm 15.8 \mu \mathrm{g} / \mathrm{mg})$ than in $\mathrm{RCSF}_{\text {fam }}(63.0 \pm 27.4 \mu \mathrm{g} / \mathrm{mg}$ of protein, NS).

Measurements of calcium oxalate crystal aggregation

Values of inhibitory activity toward COM crystal aggregation by $40 \mathrm{mg} / \mathrm{L}$ of THP widely overlapped between pro-

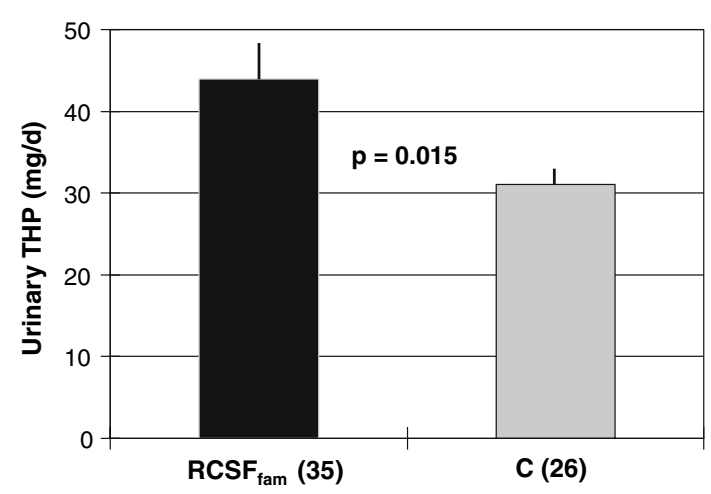

Fig. 2 Daily urinary THP excretion rates in $\mathrm{RCSF}_{\text {fam }}$ and C 



Fig. 3 Results of sialic acid measurements in whole native 24-h urines (a) as well as crude salt precipitates from whole urines and salt-precipitated and purified THPs (b). For details, see text

teins from $\mathrm{C}$ (range -39.8 to $+82.7 \%$ ) and from $\mathrm{RCSF}_{\text {fam }}$ (range -62.0 to $+84.2 \%$ ), but were significantly higher for THPs from $\mathrm{C}(24.9 \pm 6.0 \%)$ than from $\mathrm{RCSF}_{\text {fam }}$ $(-6.1 \pm 5.5 \%, P=0.022$ vs. control THPs), as depicted in Fig. 4. Under the experimental conditions of the present study (pH 5.70, $200 \mathrm{mM} \mathrm{NaCl}$ ), 25 out of 34 (73.5\%) THPs from controls were inhibitory, compared with 25 out of 44 THPs $(56.8 \%)$ from $\operatorname{RCSF}_{\text {fam }}\left(\chi^{2}=4.84, P<0.05\right)$. Crystal aggregation measurements were not significantly related to any of the analytical measures, i.e., THP excretion rates, SA measurements or electrophoretic patterns, neither in $\mathrm{RCSF}_{\text {fam }}$ nor in C.

\section{Discussion}

This study demonstrates that every seventh patient with recurrent idiopathic calcium renal stone disease referred to our stone clinic had a positive family history, defined as history of kidney stones in parents, grandparents, siblings, uncles or aunts $\left(\mathrm{RCSF}_{\text {fam }}\right)$. The study represents the largest

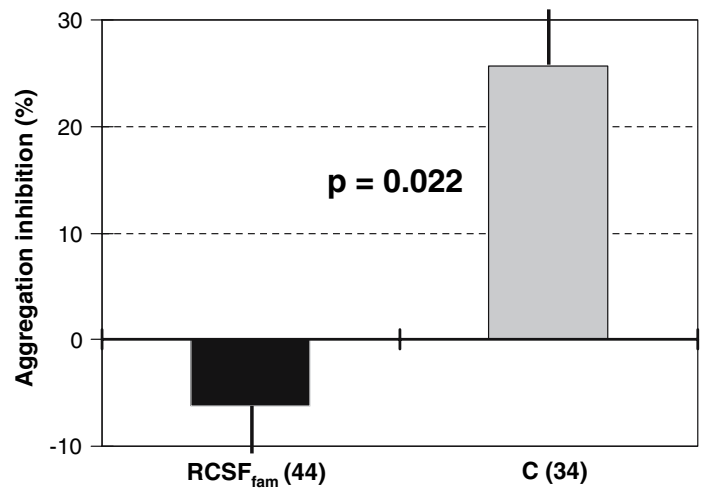

Fig. 4 Inhibition of calcium oxalate monohydrate crystal aggregation in vitro by $40 \mathrm{mg} / \mathrm{L}$ of purified THP at pH 5.70 and $200 \mathrm{mM} \mathrm{NaCl}$. For details, see text. Negative value for inhibition $=$ promotion of crystal aggregation investigation on urinary THP in a group of such highly selected $\mathrm{RCSF}_{\text {fam }}$. Our main findings are that (1) $\mathrm{RCSF}_{\text {fam }}$ excrete significantly more THP than age-matched controls, (2) THPs from $\mathrm{RCSF}_{\text {fam }}$ and C are structurally different, as demonstrated by elution patterns from an analytical column and SA measurements and (3) THP molecules from RCSFfam are weaker inhibtors of calcium oxalate crystal aggregation than normal THPs.

Several studies have looked at urinary excretion rates of THP in kidney stone formers and healthy controls. In studies using quantitative electroimmunodiffusion, THP excretion rates were $40-50 \mathrm{mg} /$ day, without differences between stone formers and healthy subjects [21, 22]. More recent studies used radioimmunoassay or ELISA and demonstrated that THP excretion rates varied more widely among subjects, generally ranging between 10 and $70 \mathrm{mg} /$ day [17, 23-26]. THP excretion rates were either equal to healthy controls $[23,24]$ or reduced in "common" stone formers $[17,25,26]$. The latter was at least partly due to the fact that some studies included uric acid stone formers in whom ELISA measurements have indicated lower THP excretions rates $[17,27]$. The increased amounts of urinary THP measured in $\mathrm{RCSF}_{\text {fam }}$ in the present study may reflect a truly increased renal THP production. However, they might also result from an increased number of THP-binding sites exposed to the THP antibody, due to conformational changes in proteins from $\mathrm{RCSF}_{\text {fam }}$.

Indeed, conformational alterations appear to be operational, as suggested by the delayed elution of lyophilized stone former THPs from a Sepharose column. A very similar pattern was found in a small number of stone formers in a previous study where delayed elution from a Sephacryl S200 column in THPs from stone formers, but not from healthy controls, occurred [15]. Apparently, THP molecules after salting-out from whole urine occur in at least two different states of molecular aggregation, and urines of $\mathrm{RCSF}_{\text {fam }}$ contain relatively more aggregated THP which predisposes to delayed elution from an analytical column. These findings are in keeping with our previous work demonstrating increased viscosities and higher apparent molecular masses of stone former THP isolated from whole urine under the same experimental conditions $[14,15]$.

The role of SA content of THP molecules with respect to urinary stone formation has been addressed previously. Knörle et al. [16] compared individually purified THPs from ten healthy controls and ten recurrent calcium oxalate stone formers and found that stone formers' THPs contained significantly less SA. Similar findings were most recently obtained by Sumitra et al. [28], who compared 100 controls and 200 not-further-specified hyperoxaluric renal stone formers. Using the same thiobarbituric assay, we measured $49 \pm 10 \mu \mathrm{g} / \mathrm{mg}$ THP in controls, identical to the $51 \pm 9 \mathrm{~g} / \mathrm{kg}$ and the $50 \pm 6 \mu \mathrm{g} / \mathrm{mg}$ THP obtained in healthy 
controls by Knörle et al. [16] and Sumitra et al. [28], respectively. Differences between these studies and our investigation, however, exist in stone former THPs: SA content of THP in our highly selected $\mathrm{RCSF}_{\text {fam }}$ was $75 \pm 9 \mu \mathrm{g} / \mathrm{mg}$ THP, higher than the $21 \pm 4 \mathrm{~g} / \mathrm{kg}$ in the ten stone formers of Knörle et al. [16] and the $28 \pm 3 \mu \mathrm{g} / \mathrm{mg}$ in the 200 hyperoxaluric stone formers of Sumitra et al. [28]. We did not obtain data on SA contents of THPs from "ordinary" calcium stone formers without positive family history, but based on the identical SA contents of normal THPs in three different studies [16, 28, present work], the difference in SA content of stone former THPs between our study and the studies by Knörle et al. [16] and Sumitra et al. [28] is highly unlikely to be due to analytical differences. It may rather reflect a specific molecular abnormality of THP in our highly selected recurrent calcium stone formers with positive family history.

This study confirms once more that aggregation of COM crystals is modulated by the presence of THP at physiologic concentrations. Furthermore, we again find reduced crystal aggregation inhibition or even aggregation promotion by THPs from recurrent stone formers, at least under conditions of physiologically high ionic strength at solution $\mathrm{pH}$ $5.7[14,15]$. Previous data indicated that THP function, i.e., crystal aggregation inhibition, was significantly related to THP structure, assessed by measurements of intrinsic viscosity [14]. In the present study, we did not find a correlation between THP function and structural data, i.e., elution patterns of THP molecules. Most likely, intrinsic viscosity is a more accurate index of molecular THP conformation with respect to THP interaction with urinary crystals.

At this point, it has to be emphasized that human urine contains many molecules which act as modulators of crystallization [29]. Obviously, one single molecule such as THP cannot be considered fully responsible for all modulatory actions on urinary crystallization and crystal retention. Furthermore, interactions between various crystallization modulators, as demonstrated for instance for citrate and THP $[14,24]$, ought to be considered; this was beyond the scope of the present study. Moreover, animal models and renal cell culture studies show increased synthesis of THP as well as of other inhibitory macromolecules on exposure to high oxalate and/or calcium oxalate crystals $[10,29]$. It therefore seems reasonable to envision that intermittent high peaks of urinary oxalate concentrations (for instance after meals), although not detected by routine 24-h urine analysis, may induce a rise in the synthesis of potentially "harmful" macromolecules such as THP in genetically predisposed individuals.

In conclusion, our study confirms that THP plays a role in calcium oxalate crystal aggregation and in the formation of calcium oxalate stones. We demonstrate for the first time that severely recurrent idiopathic calcium stone formers with a positive family history excrete significantly higher amounts of structurally different THP molecules with higher SA contents than age-matched healthy controls. These abnormal stone former THPs are less inhibitory or even promotive toward calcium oxalate crystal aggregation, apparently one of the more important prerequisites for urinary stone formation [7-9]. One can only speculate about the possibility that such abnormal urinary macromolecules might also facilitate the deposition of urinary crystal aggregates on preformed Randall's plaques in the ducts of Bellini [30].

Acknowledgments The study was partly supported by the Swiss National Science Foundation (Grant 32-43448.95) and by PHSN/ NIDDK (grant DK 56788-06).

\section{References}

1. Kumar S, Muchmore A (1990) Tamm-Horsfall protein-Uromodulin (1950-1990). Kidney Int 37:1395-1401

2. Serrafini-Cessi F, Malagolini N, Cavallone D (2003) Tamm-Horsfall glycoprotein: biology and clinical relevance. Am J Kidney Dis 42:658-676

3. Pak J, Pu Y, Zjang Z-T, Hasty DL, Wu X-R (2001) Tamm-Horsfall protein binds to type 1 fimbriated Escherichia coli and prevents $E$. coli from binding to uroplakin Ia and Ib receptors. J Biol Chem 276:9924-9930

4. Bates JM, Raffi HM, Prasadan K, Mascarenhas R, Laszik Z, Maeda N, Hultgren SJ, Kumar S (2004) Tamm-Horsfall protein knockout mice are more prone to urinary tract infection: rapid communication. Kidney Int 65:791-797

5. Wimmer T, Cohen G, Saemann MD, Hörl WH (2004) Effects of Tamm-Horsfall protein on polymorphonuclear leukocyte function. Nephrol Dial Transplant 19:2192-2197

6. Mo L, Huang H-Y, Zhu X-H, Shapiro E, Hasty DL, Wu X-R (2004) Tamm-Horsfall protein is a critical renal defense factor protecting against calcium oxalate crystal formation. Kidney Int 66:1159-1166

7. Hess B, Kok DJ (1996) Nucleation, growth and aggregation of stone-forming crystals. In: Coe FL, Favus MJ, Pak CYC, Parks JH, Preminger GM (eds) Kidney stones: medical and surgical management, Chap. 1. Lippincott-Raven Publishers, Philadelphia

8. Fleisch H (1987) Inhibitors and promoters of stone formation. Kidney Int 13:361-371

9. Kok DJ, Khan SR (1994) Calcium oxalate nephrolithiasis, a free or fixed particle disease. Kidney Int 46:847-854

10. Khan SR (1997) Tubular surface events during nephrolithiasis. Curr Opin Urol 7:240-247

11. Scurr DS, Robertson WG (1986) Modifiers of calcium oxalate crystallization found in urine. II. Studies on their mode of action in an artificial urine. J Urol 136:128-131

12. Hess B (1994) Tamm-Horsfall glycoprotein and calcium nephrolithiasis. Miner Electrolyte Metab 20:393-398

13. Hess B, Nakagawa Y, Coe FL (1989) Inhibition of calcium oxalate monohydrate crystal aggregation by urine proteins. Am J Physiol 257:F99-F106

14. Hess B, Zipperle L, Jaeger Ph (1993) Citrate and calcium effects on Tamm-Horsfall glycoprotein as a modifier of calcium oxalate crystal aggregation. Am J Physiol 265:F784-F791

15. Hess B, Nakagawa Y, Parks JH, Coe FL (1991) Molecular abnormality of Tamm-Horsfall glycoprotein in calcium oxalate nephrolithiasis. Am J Physiol 260:F569-F578 
16. Knörle R, Schnierle P, Koch A, Buchholz N-P, Hering F, Seiler H, Ackermann T, Rutishauser G (1994) Tamm-Horsfall glycoprotein: role in inhibition and promotion of renal calcium oxalate stone formation studied with Fourier-transform infrared spectrometry. Clin Chem 40:1739-1743

17. Glauser A, Hochreiter W, Jaeger Ph, Hess B (2000) Determinants of urinary excretion of Tamm-Horsfall protein in non-selected kidney stone formers and healthy subjects. Nephrol Dial Transplant 14:1580-1587

18. Reinhart HH, Obedeanu N, Walz D, Sobel JD (1989). A new ELISA method for the rapid quantification of Tamm-Horsfall protein in urine. Am J Pathol 92:199-205

19. Fletcher AP, Neuberger A, Ratcliffe WA (1970) Tamm-Horsfall urinary glycoprotein: the chemical composition. Biochem J $120: 417-424$

20. Aminoff D (1961) Method for the quantitative estimation of $N$ acetylneuraminic acid and their application to hydrolysates of sialomucoids. Biochem J 81:384-392

21. Bichler KH, Kirchner Ch, Ideler V (1976) Uromucoid excretion in normal individuals and stone formers. Br J Urol 47:733-738

22. Samuell CT (1979) Uromucoid excretion in normal subjects, calcium stone formers and in patients with chronic renal failure. Urol Res 7:5-12

23. Thornley C, Dawnay A, Cattell WR (1985) Human Tamm-Horsfall glycoprotein: urinary and plasma levels in normal subjects and patients with renal disease determined by a fully validated radioimmunoassay. Clin Sci 68:529-535

24. Erwin DT, Kok DJ, Alam J, et al (1994) Calcium oxalate stone agglomeration reflects stone forming activity: citrate inhibition depends on macromolecules larger than 30 kilodaltons. Am J Kidney Dis 24:893-900

25. Romero MC, Nocera S, Nesse AB (1997) Decreased Tamm-Horsfall protein in lithiasic patients. Clin Biochem 30:63-67

26. Ganter K, Bongartz D, Hesse A (1999) Tamm-Horsfall protein excretion and its relation to citrate in urine of stone-forming patients. Urology 53:492-495

27. Bichler KH, Mittermüller B, Strohmaier WL, Feil G, Eipper E (1999) Excretion of Tamm-Horsfall protein in patients with uric acid stones. Urol Int 62:87-92

28. Sumitra K, Pragasam V, Sakthivel R, Kalaiselvi P, Varalakshmi P (2005) Beneficial effects of vitamin E supplementation on the biochemical and kinetic properties of Tamm-Horsfall glycoprotein in hypertensive and hyperoxaluric subjects. Nephrol Dial Transplant 20:1407-1415

29. Khan SR (2004) Role of renal epithelial cells in the initiation of calcium oxalate stones. Nephron Exp Nephrol 98:e55-e60

30. Coe FL, Evan A, Worcester E (2005) Kidney stone disease. J Clin Invest 115:2598-2608 